\title{
Is the colon mucosa affected by ten days of gastric restriction in an animal model? ${ }^{1}$
}

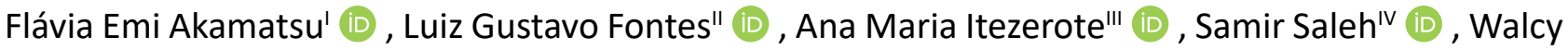

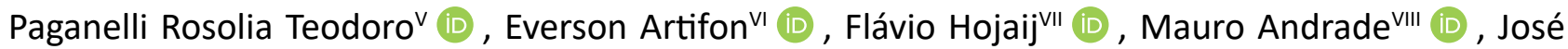 \\ Aires Pereira $^{\mathrm{IX}}$ (D) , Carlos Augusto Real Martinez ${ }^{\mathrm{X}}$ (D) , Alfredo Luiz Jacomo ${ }^{\mathrm{XI}}$ (D)
}

I PhD, Department of Surgery, Laboratory of Medical Research 02, Division of Human Structural Topography, Faculty of Medicine, Universidade de São Paulo (FMUSP), Brazil. Design, intellectual and scientific content of the study; manuscript writing.

" Graduate student, Division of Human Structural Topography, FMUSP, Sao Paulo-SP, Brazil. Acquisition of data, technical procedures.

II' PhD, Department of Surgery, Laboratory of Medical Research 02, Division of Human Structural Topography, FMUSP, Sao Paulo-SP, Brazil. Acquisition of data, technical procedures.

Iv PhD, Department of Surgery, Laboratory of Medical Research 02, Division of Human Structural Topography, FMUSP, Sao Paulo-SP, Brazil. Acquisition of data, technical procedures.

$\checkmark$ PhD, Department of Rheumatology, Laboratory of Medical Research-Medical Clinica, FMUSP, Sao Paulo-SP, Brazil. Technical procedures, interpretation of data.

VI PhD, Department of Surgery, Division of Human Structural Topography, FMUSP, Sao Paulo-SP, Brazil. Statistical analyses, critical revision.

VII PhD. Department of Surgery Medicine, Laboratory of Medical Research 02, FMUSP, Sao Paulo-SP, Brazil. Technical procedures, interpretation of data.

VIII PhD, Department of Surgery, Laboratory of Medical Research 02, Division of Human Structural Topography, FMUSP, Sao Paulo-SP, Brazil. Interpretation of data, manuscript writing, critical revision.

Ix PhD, Department of Health Science, Universidade São Francisco (USF), Bragança Paulista-SP, Brazil. Technical procedures, histological examinations.

$x$ PhD, Department of Health Science, USF, Bragança Paulista-SP, Brazil. Conception of the study, analysis and interpretation of data.

XI PhD, Department of Surgery, Laboratory of Medical Research 02, Division of Human Structural Topography, FMUSP, Sao Paulo-SP Brazil. Conception, intellectual and scientific content of the study, critical revision.

\begin{abstract}
Purpose: To identify whether the colon mucosa is affected by ten days of gastric restriction in an animal model.

Methods: An experimental model of gastric restriction was devised using rats. The animals were submitted to surgical gastrostomy, and a cylindrical loofah was inserted into the stomach. We studied 30 adult male Wistar rats divided into three groups: the stomach restriction group (R10); the sham group (S10), which underwent the same procedure except for the loofah insertion; and the control group (C10). The expression of neutral and acid mucins was evaluated using histochemical techniques. Goblet cells and protein content were compared between groups using generalized estimation equations (GEEs). Bonferroni's multiple comparison was applied to identify differences between the groups. All tests considered a 5\% significance level.

Results: There was an increased expression of neutral mucins, acid mucins and goblet cells in the R10 group. Collagen was also enhanced in the R10 group.

Conclusion: The colon mucosa is affected by ten days of gastric restriction in an animal model, increasing neutral mucins, acid mucins and collagen content with trophic maintenance.
\end{abstract}

Key words: Models, animal. Colon. Mucins. Rats. 


\section{- Introduction}

Obesity is a global epidemic ${ }^{1}$, and in adulthood, it is a major risk factor for the world's leading causes of poor health and early death, including cardiovascular disease, several common cancers, diabetes and osteoarthritis ${ }^{2}$. The burden of disease generated from the high prevalence and consequences of obesity makes it a true global public health concern ${ }^{3}$. The only proven long-term treatment for severe obesity on a population level is the surgical modification of the gastrointestinal anatomy to induce weight loss, termed bariatric surgery ${ }^{4}$. Bariatric surgery, also called weight loss surgery or metabolic surgery, was introduced 50 years ago to provide drastic weight loss in morbidly obese patients ${ }^{5,6}$, and its use is currently increasing to treat patients with high adiposity, or occasionally for metabolic benefits ${ }^{7}$. The most successful types of bariatric surgery involve limiting the absorption of nutrients (malabsorption), reducing the size of the stomach to decrease the total nutrient intake (restriction), and reducing hunger and satiety by altering gut hormones (metabolic) ${ }^{3}$. Sleeve gastrectomy $(\mathrm{SG})$, gastric bypass, gastric banding, and gastric plication (GP) are the most common procedures used to treat obesity ${ }^{8}$. However, recent studies have suggested serious complications that may result from weight reduction surgery, such as nutritional deficiencies ${ }^{9-13}$, the acceleration of nephropathy ${ }^{14}$, modification of the hippocampus cytoarchitecture ${ }^{15}$, changes in gene expression for subcutaneous fat and arcuate hypothalamic nucleus ${ }^{16}$ and modifications in bone metabolism, accelerating the process of osteoporosis ${ }^{17}$. A body weight loss of $15 \%$ or more is associated with the loss of $20 \%$ of the body's protein ${ }^{18}$. Recently, authors have reported constipation after bariatric surgery with diet, due to decreased bowel motility and prolonged bowel movement ${ }^{19}$. Restrictive diets and bariatric surgery related to nutrient deficiency rather than weight loss surgery reduce the microbial abundance and promote changes in the microbial composition that could have longterm, detrimental effects on the colon ${ }^{20}$. Goblet cells reside throughout the length of the small and large intestine and are responsible for the production and maintenance of the protective mucus blanket by synthesizing and secreting high-molecular-weight glycoproteins known as mucins. The tissue content and pattern of mucin expression in goblet cells change in patients with colorectal cancer, ulcerative colitis, intestinal infections, inflammatory bowel disease (IBD), cystic fibrosis (CF), and diversion colitis ${ }^{21-23}$. Disruption in the intestinal homeostasis results in a defective mucus barrier with increased permeability, which results in inflammation and injury of the intestinal mucosal cells $\mathbf{s}^{24,25}$. Studies in experimental models have demonstrated that a deficiency in the supply of short-chain fatty acids (SCFAs) to the colon, devoid of transit, can modify proteins related to the intercellular junction systems, allowing the development of exclusion colitis $22,26,27$. SCFAs influence colonic health through various mechanisms. In vitro and ex vivo studies have shown that SCFAs have anti-inflammatory and anticarcinogenic effects, play an important role in maintaining metabolic homeostasis in colonocytes, and protect colonocytes from external harm ${ }^{28,29}$

The effect on the colon caused by malnutrition due to gastric restriction surgeries in the stomach has not yet been studied. The objective of the present study is to evaluate and quantify the acid and neutral mucin contents, as well as the number of goblet cells in the colon and their respective crypts, of rats submitted to gastric restriction for 10 days. We also intend to correlate any changes found with acute weight loss, with the aim of contributing to the effectiveness and safety of this therapy that has been increasing worldwide.

\section{- Methods}

\section{Animals and experimental protocol}

This study was approved by the Ethics Committee for the Analysis of Research Projects (Protocol 065/13). All animals received humane care in compliance with the experimental protocols of the Ethical Principles in Animal Experiments adopted by the Brazilian Association of Animal Testing.

Thirty adult male Rattus norvegicus albinus Wistar animals weighing 250 to $300 \mathrm{~g}$ were housed in the Universidade de São Paulo, School of Medicine's facilities. Five animals were housed per cage and were given food and purified tap water ad libitum. The animals were operated on in the Center for Study and Research in Surgery (CEPEC), Department of Urology of the Faculty of Medicine. The animals were divided into three groups: the stomach restriction group (R10), the sham group (S10), which underwent the same procedure except for the loofah insertion, and the control group (C10). Animals were fed and kept in separate cages. They were weighed every other day until being sacrificed on day 10 .

\section{Surgery to promote gastric reduction}

To reduce the gastric capacity and cause significant weight loss in rats without developing anemia, a surgical procedure was performed, similar to that described by Tolosa et $a l^{.^{30}}$. After 12 hours of fasting, the rats were anesthetized by isoflurane $4 \%$ vaporization. Anesthesia was continued through a mask with $1.5-3 \%$ isoflurane inspired fraction, and the rats were submitted to median laparotomy and gastrostomy in the greater curvature of the stomach 
for the implantation of a cylindrical Luffa bush (loofah; 1.5 $\mathrm{cm}$ in diameter) made of cylindrical Luffa (an experimental phytobezoar). The gastrostomy was closed with continuous mononylon suture yarn 6.0 , and the abdominal wall was closed in two planes: the aponeurosis, with 4.0 mononylon suture yarn, and the skin, with 3.0 plain cotton stitches. The animals in the sham group were exposed to the same surgical procedure described above but were not submitted to phytobezoar implantation. Tramadol hydrochloride (20-40 mg/kg) was administered intraperitoneally, with a frequency of at least 12 hours for 5 days ${ }^{31}$.

\section{Experimental groups}

On day 1 , the animals were divided into three groups of 10 animals: one group underwent surgery for stomach restriction (R10), with both the sham controls (S10) and normal controls (C10). Each animal was weighed every two days until the day of euthanasia.

\section{Euthanasia and material collection}

After the experimental period, the animals were euthanized with carbon dioxide $\left(\mathrm{CO}_{2}\right)$. This gas is lethal because it causes depression of the central nervous system. The animals were kept in the chamber for more than 10 minutes to confirm their death ${ }^{32}$. Two colon samples were collected $2 \mathrm{~cm}$ from the cecum and were individually packed into containers. Samples were submitted to routine histological processing for Hematoxylin-Eosin (HE), Alcian Blue $(A B)$, Periodic Acid-Schiff (PAS), High Iron Diamine (HID-AB) and Picrosirius Red staining.

\section{Histological morphometric analysis}

The Zeiss Microscope Imager.A2 was used for the analysis of the slides with $\mathrm{HE}$. The images were captured by a camera coupled with the AxioVision Release 4.8.1 program. The entire length of the crypts of the colon mucosa was measured and the goblet cells were counted, with three crypts per field. We used six fields per sheet from the control, sham and experimental groups, which were analyzed at a magnification of $x 400$. We also analyzed the inflammatory infiltration in the colon mucosa. Polymorphonuclear and lymphomononuclear cell counts were performed in three areas of the inflammatory infiltration. Inflammatory cell counts were performed in a fraction of the inflammatory cell area. Polymorphonuclear and lymphomononuclear cells were counted in six fields of the area of inflammatory infiltration. The number of inflammatory cells was expressed by dividing the number of cells by the area of the infiltration.

Mucins were quantified in the colon of the control, sham and experimental groups using a computer-assisted image analysis. Briefly, an image analysis system consisting of an Olympus camera mounted on a microscope sent the images to a monitor using a computer-controlled (Pentium $1330 \mathrm{MHz}$ ) digitizing system (Oculus TCX, Coreco Inc., St. Laurent, Quebec, Canada). The images were processed by Image-Pro Plus 7.0 software (Media Cybernetics, Inc., Bethesda, MD, USA). For each lamina, three crypts per field were measured, and six fields per sheet from the control, sham and experimental groups were analyzed at a magnification of $x 400$. The mucin content in this compartment was expressed as the number of mucins divided by the total area studied. The final results were expressed as the number of mucins per total area. The measure of the tissue content of Picrosirius Red was analyzed with the same methodology as described above utilizing a polarized light.

\section{Statistical analysis}

Weight, goblet and inflammatory cell and mucin tissue expression (PAS, $A B$, and HID-AB) were presented by groups as the mean, median, minimum and maximum.

Between-group comparisons were made using generalized estimation equations (GEE) for data with a normal distribution, as well as an identity link function, supposing an exchangeable correlation matrix between fields ${ }^{33}$. Inflammatory cells were compared between groups and types using GEE with Poisson distribution due to cell absence. Bonferroni's multiple comparison was applied to identify differences between groups ${ }^{34}$. For weight, a multiple-group comparison was performed using an analysis of variance (ANOVA) followed by Bonferroni's post hoc test. To verify the correlation between the weight and height of the crypt and the cell quantity, Spearman's correlation was calculated ${ }^{35}$. To perform the analysis, IBM-SPSS software for Windows version 22 was used, and the data were tabulated using Microsoft Excel 2013 software. All tests were carried out with a significance level of $5 \%$.

\section{- Results}

The statistical analysis showed that the weight of the restricted group decreased significantly (by 9\%) in the first three days, and then increased (by $6.2 \%$ of the weight of the third day), which was conserved until the tenth day. Up to the 10th day there was a loss of approximately $4 \%$ of the initial weight. The weight of the sham group increased significantly from the first day to the tenth day, with an increase of $5.2 \%$ of the initial weight. The weight of the control group increased significantly from the first day to the tenth day, with an increase of $11 \%$ of the initial weight (Fig. 1). 


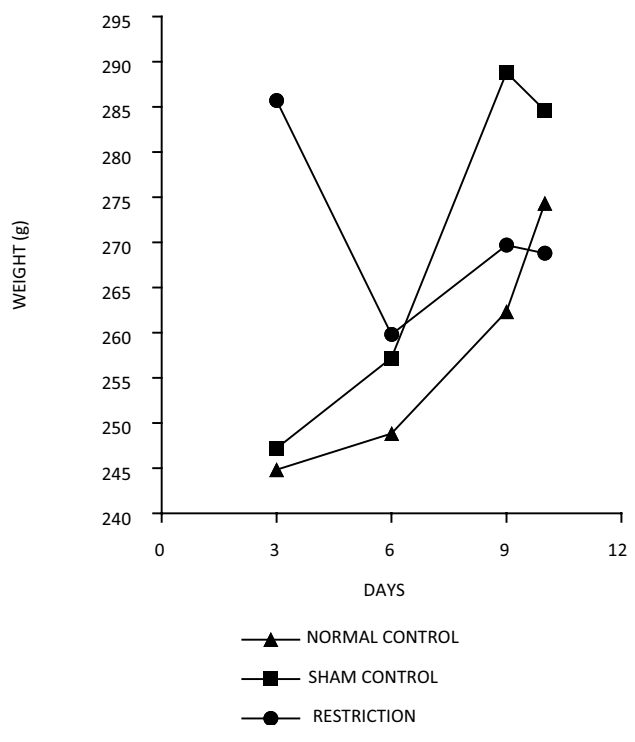

Figure 1 - The evolution of weight over 10 days in the normal, sham and restriction groups.

In the between-group comparisons of polymorphonuclear and lymphomononuclear cells, the polymorphonuclear cells and lymphocytes behaved similarly between the groups; there was a significant difference in the cell types, with pmn > lymphocytes in all groups, and there was a significant difference between the groups independent of cell type (Fig. 2). In HE, it was found that after 10 days of gastric restriction, the height

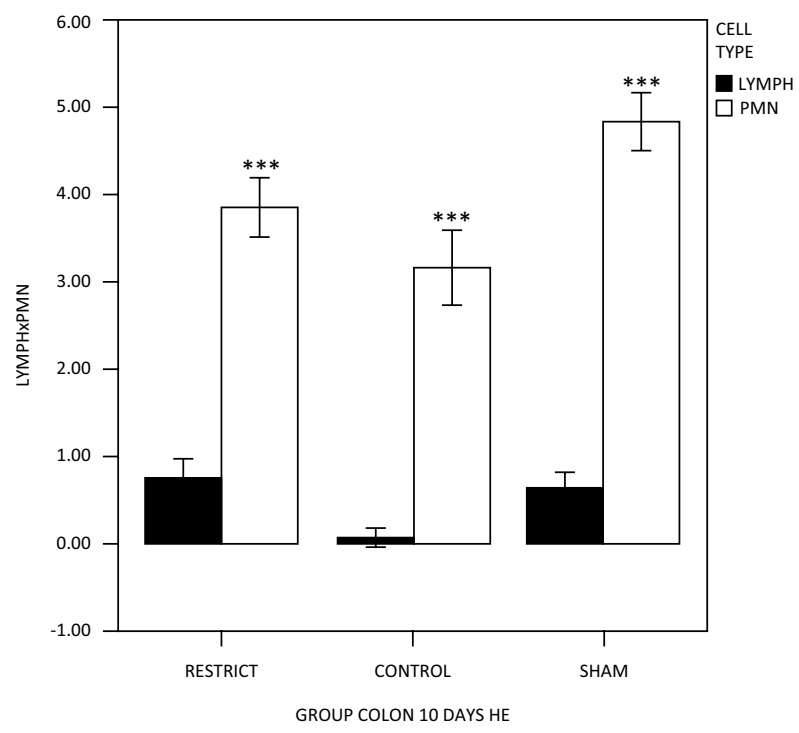

Figure 2 - Polymorphonuclear and lymphomononuclear cell counts showing similarly between the groups; a significant difference in the cell types, with pmn $>$ lymphocytes in all groups $\left(p<0.001^{* * *}\right)$. of the crypts in general decreased when compared to the sham and control animals $(p<0.05)$.

The number of goblet cells showed no difference compared to the sham group (Figs. 3 and 7). There was a trend of maintaining trophism for 10 days observed in HE (Fig. 3), with an increase in neutral mucins and their cells and an increase in acid mucins (sulfomucins) and their respective crypts (Figs. 4 and 5). There were no differences in sialomucins or sulfomucins in the restricted group compared to the sham group, as well as height and the number of cells compared to the control group. We found a significant increase in total collagen in the restricted group compared to the sham and control groups (Figs. 6 and 7).
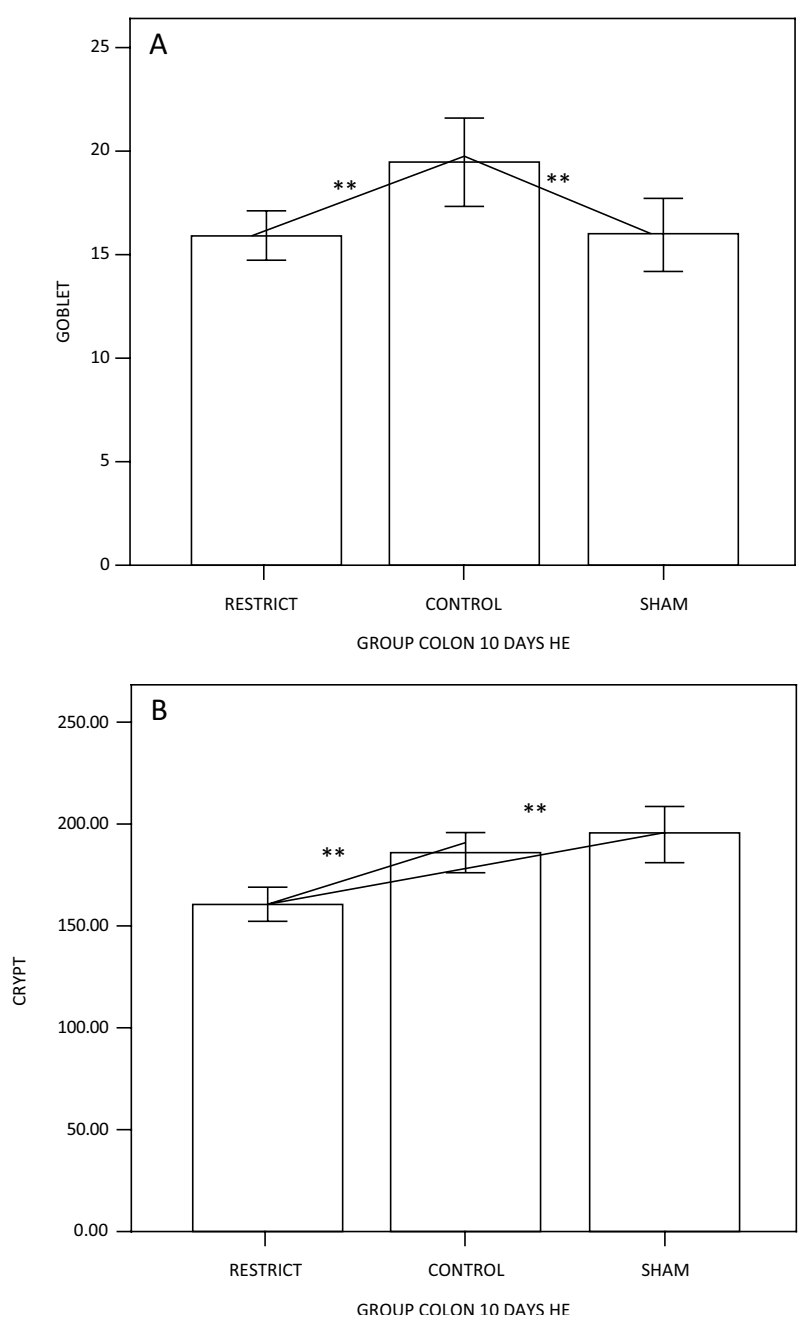

Figure 3 - (A) Goblet cell counts, showing a difference between the groups; the restricted and sham groups have fewer goblet cells than the control group. (B) Crypt height, showing the decrease in height of the restrict group when compared to the sham and control animals $\left(p<0.05^{* *}\right)$. 

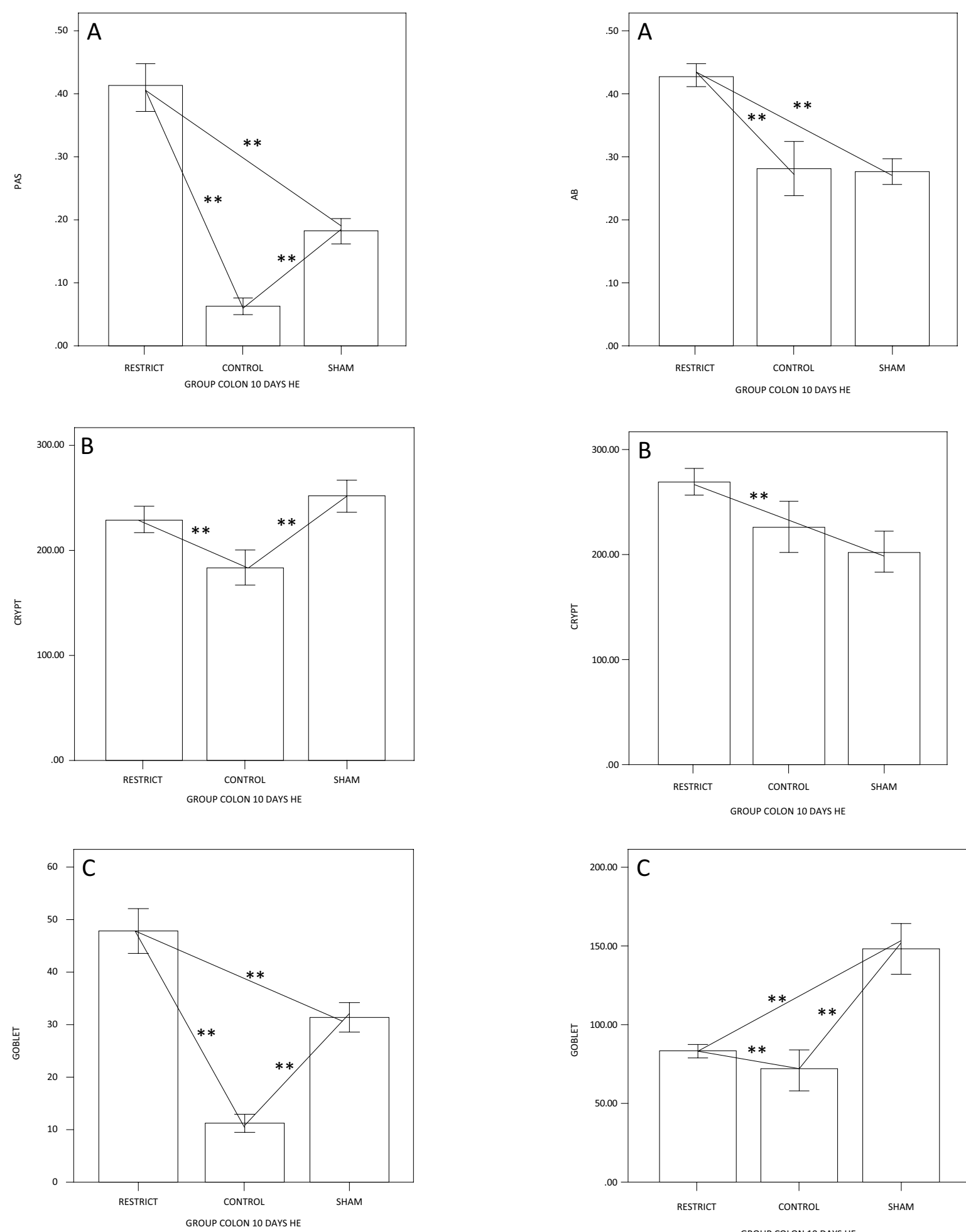

Figure 4 - (A) Semiquantification of neutral mucins; the restriction group has more neutral mucins than the other groups. (B) The difference in crypt height is only related to the control group; the goblet cells are similar to $A\left(p<0.05^{* *}\right)$.

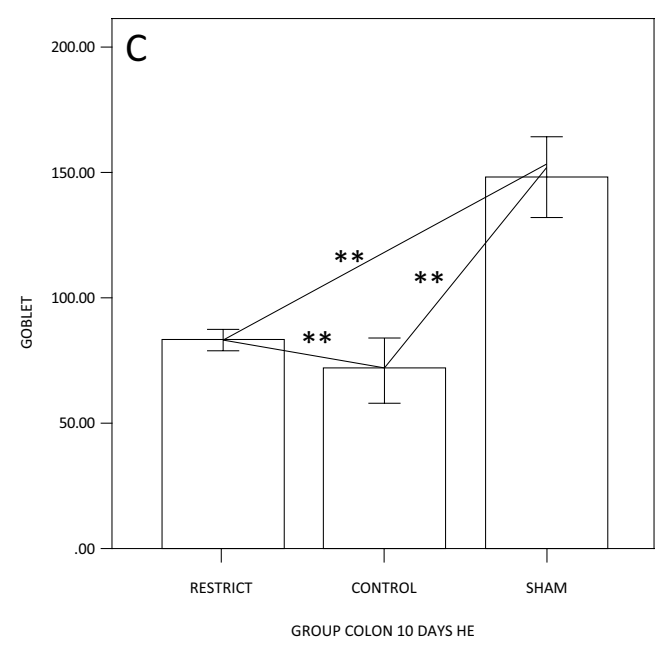

Figure 5 - (A) Semiquantification of $A B$ acid mucins; the restriction group has more acid mucins than the other groups. (B) The difference in crypt height is only related to the restricted and sham groups; the goblet cells show that the restrict group is enhanced only in relation to the control group $\left(p<0.05^{* *}\right)$. 


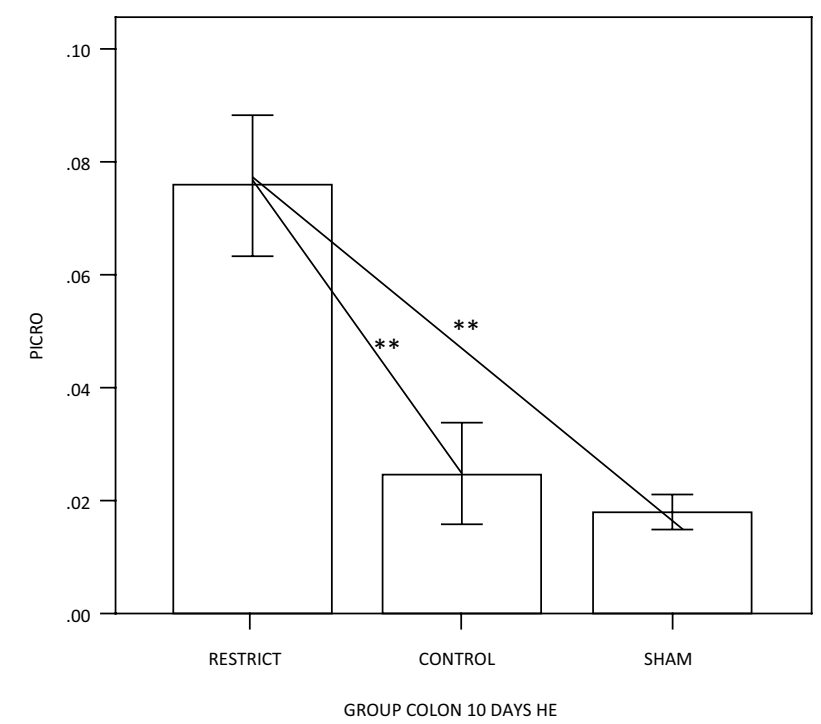

Figure 6 - Semiquantification of total collagen: collagen was enhanced in the restrict group compared to the control and sham groups $\left(\mathrm{p}<0.05^{* *}\right)$.

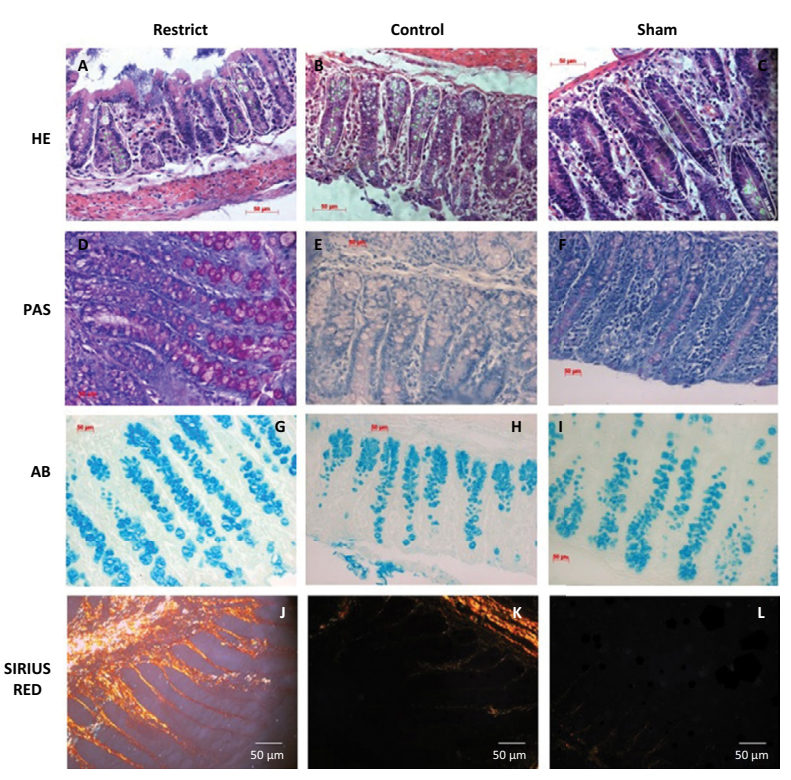

Figure 7 - Goblet cells x400: (A-C) HE; (D-F) PAS; (G-H) $A B ;(J-L)$ Sirius Red. Not much difference can be observed between the crypts in A, B and C. There are more goblet cells in $\mathbf{D}$ and $\mathbf{G}$. In $\mathrm{J}-\mathrm{L}$, the restrict group has more collagen than the control and sham groups.

There was no correlation of weight with the goblet cells stained by PAS, AB, or HID-AB ( $p=0.051$ ), and although not significant, these data indicate that for the height of the crypt controlled for PAS, the weight and height of the crypt increase.
There was a correlation between control weight and polymorphonuclear control cells; when polymorphonuclear cells increased, weight decreased.

\section{- Discussion}

Experimental bariatric surgery was performed to prevent weight gain. Studies in animals have shown that groups of rats or mice often gain weight over the observation period of a study ${ }^{36}$, and we consider this model to be efficient for experimental gastric restriction. Not only was weight gain prevented in the restrict group, but weight was lost in 10 days; a total of $4 \%$ of the initial weight. The control and sham groups gained weight over the 10 -day study period; $11 \%$ and $5.2 \%$, respectively, of the initial weight gained.

Regarding the inflammatory cells, polymorphonuclear cells were enhanced in all groups compared to lymphomononuclear cells, which was significant between the groups, showing inflammation compared to the control group but not different from the sham group. This inflammatory response probably occurred due to the presence of the phytobezoar, which may also have contributed to a decrease in the supply of nutrients to the intestines. To evaluate the evolution of this inflammatory response, it may be necessary to increase the time of exposure to the phytobezoar.

Experimental studies have shown a reduction in height of the colonic glands in the colonic mucosa devoid of the fecal stream ${ }^{26}$. The authors suggest that a lack of SCFA supply and the oxidative stress in the colonic mucosa without a fecal stream are the main factors associated with colonic gland atrophy. In this study, we found that after 10 days of gastric restriction, the height of the crypts in general decreased compared to the sham and control groups. This has also occurred in experimental models of diversion colitis, where food restriction due to a phytobezoar probably led to the atrophy of the colonic glands. Interestingly, no differences were seen in the number of goblet cells. Controversies exist regarding the population of cells in colonic segments devoid of the fecal stream ${ }^{37,38}$. It is possible that the different results found in relation to the goblet cell population in the colonic mucosa restricting the regular supply of SCFAs may be related to the different exclusion times adopted in the experiment durations of different studies 22 .

The major function of intestinal goblet cells is the formation of mucus layers, which represent the first line of defense in the colonic epithelium ${ }^{22,27}$. Intestinal mucus layers secreted by goblet cells are 
rich in mucins, which provide the frontline defense of the host against endogenous and exogenous irritants and microbial attachment and invasion, but allow the transport of nutrients ${ }^{24,25}$. In most intestinal infections, the induction of goblet cells and mucin synthesis and secretion occur frequently during the acute phase. However, chronic infection results in the depletion of goblet cells ${ }^{24,25,39}$. Neutral mucins were enhanced even though their goblet cells did not increase, although the height of the crypt became higher. Neutral mucins represent the main subtype of mucins in the right colon, and the content of this type of mucins usually undergoes minor modifications in the colonic mucosa without a regular supply of feces ${ }^{22}$. SCFAs are crucial for intestinal health because they serve as the major energy substrates for colonocytes and have antiinflammatory and anti-carcinogenic properties ${ }^{40}$. Furthermore, under germfree conditions, neutral mucins in the colon are higher ${ }^{41}$. The proportions between neutral and acid mucins in rats also occur in men and are usually constant in the colonic mucosa ${ }^{42,43}$. However, the tissue content of acidic mucins can be modified with food restriction, which should influence how the nourishment of the colonic mucosa interferes with the production and absorption of SCFAs ${ }^{22,44}$. This feature may be associated with intestinal barrier dysfunction $24,25,39,40,45,46$. The tissue content of total acid mucins was not increased. The proportion between sulfomucins and sialomucins is usually constant in the mucosa of normal colon tissue, but may undergo changes in various illnesses ${ }^{41,46}$.

One study showed that in the colonic mucosa without a fecal stream, the tissue content of sialomucins decreased, and this reduction was related to the time of fecal exclusion ${ }^{27}$ Gastric restriction substantially reduces the supply of fibers to the colon, thereby reducing the production of SCFAs ${ }^{26}$. This lower supply of SCFAs to the colonic mucosa, the main substrate for epithelial cells, causes less mucin production, as demonstrated by studies that measured the glycoprotein content in the colonic mucosa devoid of a fecal stream ${ }^{22,27}$. In this study, it is possible that we did not find modifications in the tissue content of sialomucins because a phytobezoar does not completely prevent the passage of SCFAs into the colon, thus maintaining a content of sialomucins similar to that of the sham group. Additionally, under germfree conditions, the ratio of neutral to acidic mucins in the colon is higher, and sulfomucins appear to increase at the expense of sialylated mucins ${ }^{48,-51}$. Similar to other authors who studied the tissue content of sialomucins in the colonic mucosa devoid of a fecal stream, we also found a lower expression of sialomucins and no difference in sulfomucins. It is likely that due to the incomplete absence of food, the acid mucins were not reshaped, but the goblet cells that express the sulfomucins were enhanced. This phenomenon could be triggered by the food restriction at the time. In general, trophism is conserved with the enhancement of neutral mucins. Collagen was enhanced in the restrict group, probably due to the inflammatory process triggered by gastric restriction.

To the best of our knowledge, no studies have quantified the expression patterns of acid and neutral mucins in an experimental model with gastric restriction.

Epithelial integrity, mucus production, and the presence and equilibrium of commensal bacteria interfere directly with the immunity of the intestinal barrier. The gastrointestinal epithelium is protected by a layer of mucus containing glycoprotein mucins secreted against the attack of digestive fluids, microorganisms, and toxins ${ }^{52}$. The integrity of the protective mucus layer is ensured by the rapid and massive secretion of goblet cells. Intestinal inflammation and injury result from a defective mucosal barrier, abnormal commensal bacteria, and defective host innate and adaptive immunitye ${ }^{53,54}$.

Overweight and obesity have reached epidemic levels in the United States and worldwide, affecting nearly three-fourths of adults in the United States ${ }^{55-57}$. Childhood obesity is one of the most serious global public health challenges of the 21st century, affecting every country in the world. In just 40 years, the number of school-age children and adolescents with obesity has risen more than 10-fold, from 11 million to 124 million (2016 estimates) (NCD Risk Factor Collaboration [NCD-RisC] 2017). In addition, in this same population, an estimated 216 million were classified as overweight but not obese in 2016 (NCD Risk Factor Collaboration [NCD-RisC] 2017).

The condition also affects younger children, with over 38 million children under the age of 5 living with overweight or obesity in $2017^{58}$. Bariatric surgery is considered for patients with severe obesity ${ }^{57}$. This study contributes to assessing the impact of weight loss strategies and to the effectiveness and safety of gastric restriction therapy, which has been increasing worldwide.

\section{- Conclusions}

The colon mucosa is affected by ten days of gastric restriction. In an animal model of inflammatory situations, dietary restriction can promote mucin synthesis, equilibrate the gut microbiota, and thus favor colonic protection and mucosal healing. Trophism is conserved with 10 days of gastric restriction. 


\section{References}

1. WHO. Obesity and overweight. Geneva: World Health Organization; 2006. Fact Sheet No311

2. WHO/NMH/PND/ECHO/18.1. Taking action on childhood obesity report. Available from http://www.who.int/endchildhood-obesity/publications/taking-action-childhoodobesity-report/en/2018

3. Frame-Peterson LA, Megill RD, Carobrese S, Schweitzer M. Nutrient deficiencies are common prior to bariatric surgery. Nutr Clin Pract. 2017;32(4):463-9. doi: 10.1177/0884533617712701

4. Buchwald H, Buchwald JN. Evolution of operative procedures for the management of morbid obesity 19502000. Obes Surg. 2002;12:705-17. PMID: 12448398

5. Kremen, AJ, Linner JH, Nel-son, $\mathrm{CH}$. An experimental evaluation of the nutritional importance of proximal and distal small intestine. Ann Surg. 1954;140:439-48. PMID: 13198079

6. Gulcicek OB, Ozdogan K, Solmaz A, Yigitbas H, Altnay S, Gunes A, Celik DS, Yavuz E, Celik A, Celebi F. Metabolic and histopathological effects of sleeve gastrectomy and gastric plication: an experimental rodent model. Food Nutr Res. 2016;60:30888. doi: 10.3402/fnr.v60.30888

7. Ashrafian $\mathrm{H}$, Athanasiou $\mathrm{T}$, Li JV, Bueter $\mathrm{M}$, Ahmed K, Nagpal K, Holmes E, Darzi A, Bloom SR. Diabetes resolution and hyperinsulinaemia after metabolic Rouxen-Y gastric bypass. Obes Rev. 2011;12(5):e257-72. doi: 10.1111/j.1467-789X.2010.00802.x

8. Albanese A, Prevedello L, Verdi D, Nitti D, Vettor R, Foletto M. Laparoscopic gastric plication: an emerging bariatric procedure with high surgical revision rate. Bariatr Surg Pract Patient Care. 2015;10(3):93-8. PMID: 26421246

9. Salameh BS, Khoukaz MT, Bell RL. Metabolic and nutritional changes after bariatric surgery. Expert Rev Gastroenterol Hepatol. 2010;4(2):217-23. doi: 10.1586/ egh.09.67

10. Dewey $M$, Heuberger R. Vitamin D and calcium status and appropriate recommendations in bariatric surgery patients. Gastroenterol Nurs. 2011;34(5):367-74. doi: 10.1097/SGA.0b013e318229bcd0

11. Sawaya RA, Md JJ, Friedenberg L, Friedenberg FK. Vitamin, mineral, and drug absorption following bariatric surgery. Curr Drug Metab. 2012 Jun 29. [Epub ahead of print] PMID: 22746302

12. Frame-Peterson LA, Megill RD, Carobrese S, Schweitzer M. Nutrient deficiencies are common prior to bariatric surgery. Nutr Clin Pract. 2017;32(4):463-9. doi: 10.1177/0884533617712701

13. Mesureur L, Arvanitakis M. Metabolic and nutritional complications of bariatric surgery: a review. Acta Gastroenterol Belg. 2017;80(4):515-25. PMID: 29560648

14. Nasr SH, D'Agati VD, Said SM, Stokes MB, Largoza MV, Radhakrishnan J, Markowitz GS. Oxalate nephropathy complicating Roux-en-Y Gastric Bypass: an underrecognized cause of irreversible renal failure. Clin J Am Soc Nephrol. 2008;3(6):1676-83. PMID: 18701613
15. Sonoda EY, Gomes da Silva S, Arida RM, Giglio PN, Margarido NF, Martinez CA, Pansani AP, Maciel Rde $S$, Cavalheiro EA, Scorza FA. Hippocampal plasticity in rats submitted to a gastric restrictive procedure. Nutr Neurosci. 2011;14(5):181-5. PMID: 22005281

16. Xu Y, Ramos EJ, Middleton F, Romanova I, Quinn R, Chen C, Das U, Inui A, Meguid MM. Gene expression profiles post Roux-en-Y gastric bypass. Surgery. 2004;136(2):24652. PMID: 15300187

17. Pizzorno L. Bariatric surgery: bad to the bone. Part 1. Integr Med (Encinitas). 2016;15(1):48-54. PMID: 27330488

18. Hill, G.L. Understanding protein energy malnutrition. In: Disorders of nutrition and metabolism in clinical surgery. Hill GL (ed.). Understanding and management. London: Churchill Livingstone;1992. p:71-83.

19. Afshar S, Kelly SB, Seymour K, Woodcock S, Werner AD, Mathers JC. The effects of bariatric procedures on bowel habit. Obes Surg. 2016 Feb 19. [Epub ahead of print] PMID: 26894909

20. Seganfredo FB, Blume CA, Moehlecke $M$, Giongo $A$, Casagrande DS, Spolidoro JVN, Padoin AV, Schaan BD, Mottin CC. Weight-loss interventions and gut microbiota changes in overweight and obese patients: a systematic review. Obes Ver. 2017;18(8):832-51. doi: 10.1111/ obr.12541

21. Specian RD, Oliver MG. Functional biology of intestinal goblet cells. Am J Physiol. 1991;260(2 Pt 1):C183-93. PMID: 1996606

22. Nonose R, Spadari AP, Priolli DG, Máximo FR, Pereira JA, Martinez CA. Tissue quantification of neutral and acid mucins in the mucosa of the colon with and without fecal stream in rats. Acta Cir Bras. 2009;24(4):267-75. PMID: 19705025

23. Kim YS, Ho SB. intestinal goblet cells and mucins in health and disease: recent insights and progress. Curr Gastroenterol Rep. 2010;12(5):319-30. doi: 10.1007/ s11894-010-0131-2

24. Lievin-Le Moal V, Servin AL. The front line of enteric host defense against unwelcome intrusion of harmful microorganisms: mucins, antimicrobial peptides, and microbiota. Clin Microbiol Ver. 2006;19:315-37. PMID: 16614252

25. McGuckin MA, Eri R, Simms LA, Florin TH, Radford-Smith $\mathrm{G}$. Intestinal barrier dysfunction in inflammatory bowel diseases. Inflamm Bowel Dis. 2009;15(1):100-13. doi: 10.1002/ibd.20539

26. Sousa MV, Priolli DG, Portes AV Cardinalli IA, Pereira JA, Martinez CAR. Evaluation by computerized morphometry of histopathological alterations of the colon wall in segments with and without intestinal transit in rats. Acta Cir Bras. 2008;23(5):417-24. PMID: 18797685

27. Martinez CAR, Ribeiro ML, Gambero A, Miranda DDC, Pereira JA, Nadal SD. importance of oxygen free radicals in the etiopathogenesis of diversion colitis in rats. Acta Cir Bras. 2010;25(5):387-95 PMID: 20877947

28. Andoh A, Tsujikawa T, Fujiyama Y. Role of dietary fiber and short-chain fatty acids in the colon. Curr Pharm Des. 2003;9(4):347-58. PMID: 12570825 
29. van der Beek CM, Dejong CHC, Troost FJ, Masclee AAM, Lenaerts K. Role of short-chain fatty acids in colonic inflammation, carcinogenesis, and mucosal protection and healing. Nutr Rev. 2017;75(4):286-305. doi: 10.1093/ nutrit/nuw067

30. Tolosa EMC, Sakaki M.. Ferreira EAB, Margarido NF, Behmer OA, Zanotto A, Matsuda CK. Fitobezoar experimental e perda de peso em ratos. Hosp Clin Fac Med S. Paulo. 1988;43(2):87-92. PMID: 3247558

31. Huerkamp MJ. The use of analgesic in rodents and rabbits. Available from http://www.emory.edu/WHSC/MED/DAR/ Analgesic_drugs.htm

32. Nolen RS. Revision process begins for AVMA euthanasia guidelines. J Am Vet Med Assoc. 2009;235(3):246-47. PMID: 19725198

33. Mccullagh P, Nelder JA. Generalized linear models. 2ed. Chapman and Hall: New York; 1989.

34. Neter J, Kutner MH, Nachtsheim CJ, Wasserman W. Applied linear statistical models. 4ed. Irwing RD (ed.). Ilinois: 1996.

35. Kirkwood BR, Sterne JAC. Essential medical statistics. 2ed. Blackwell Science Massachusetts: 2006.

36. Lutz TA, Bueter M.the use of rat and mouse models in bariatric surgery experiments. Front Nutr. 2016;3:25. doi: 10.3389/fnut.2016.00025

37. Keli E, Bouchoucha M, Devroede G, Carnot F, Ohrant T, Cugnenc PH. Diversion-related experimental colitis in rats. Dis Colon Rectum.1997;40(2):222-8. PMID: 9075761

38. Mello Rde O, Silva CM, Fonte FP, Silva DL, Pereira JA, Margarido NF, Martinez CA. Evaluation of the number of goblet cells in crypts of the colonic mucosa with and without fecal transit. Rev Col Bras Cir. 2012;39(2):139-45. PMID: 22664521

39. Moncada DM, Kammanadiminti SJ, Chadee K. Mucin and Tolllike receptors in host defense against intestinal parasites. Trends Parasitol. 2003;19:305-11. PMID: 12855381

40. Hamer HM, Jonkers D, Venema K, Vanhoutvin S, Troost FJ \& Brummer RJ. Review article: the role of butyrate on colonic function. Aliment Pharmacol Ther. 2008;27:10419. PMID: 17973645

41. Dharmani P, Srivastava V, Kissoon-Singh V, Chadee K: Role of intestinal mucins in innate host defense mechanisms against pathogens. Innate Immun. 2009;1(2):123-35. PMID: 20375571

42. Deplancke B, Gaskins HR. Microbial modulation of innate defense goblet-cells and the intestinal mucus layer. Am J Clin Nutr. 2001;73:1131S-41S. doi: 10.1093/ ajcn/73.6.1131S

43. Agawa S, Muto T, Morioka Y. Mucin abnormality of colonic mucosa in ulcerative colitis associated with carcinoma and/or dysplasia. Dis Colon Rectum. 1988;31(5):387-9. PMID: 11393191

44. Allen DC, Connolly NS, Biggart JD. Mucin profiles in ulcerative colitis with dysplasia and carcinoma. Histopathology. 1988;13(4):413-24. PMID: 3220466

45. Mortensen PB, Clausen MR. Short-chain fatty acids in the human colon: relation to gastrointestinal health and disease. Scand J Gastroenterol Suppl. 1996;216:132-48. PMID: 8726286
46. Jenkins RT, Ramage JK, Jones DB, Collins SM, Goodacre $\mathrm{RL}$, Hunt RH. Small bowel and colonic permeability to 51Cr-EDTA in patients with activeinflammatory bowel disease. Clin Invest Med. 1988;11:151-5. PMID: 3135136

47. Arslan G, Atasever T, Cindoruk M, Yildirim IS. (51) CrEDTA colonic permeability and therapy response in patients with ulcerative colitis. Nucl Med Commun. 2001;22(9):997-1001. PMID: 11505209

48. Habib NA, Dawson PN, Krausz T, Blount MA, Kersten D, Wood CB.A study of histochemical changes in mucus from patients with ulcerative colitis, Crohn's disease and diverticular disease of the colon. Dis Colon Rectum. 1986;29:15-7. PMID: 3940799

49. Szentkuti L, Riedesel H, Enss ML, Gaertner K, von Engelhardt W. Pre-epithelial mucus layer in the colon of conventional and germ free rats. Histochem J. 1990;22:491-7. PMID: 1702088

50. Enss ML, Grosse-Siestrup H, Schmidt-Wittig U, Gartner K. Changes in colonic mucins of germfree rats in response to the introduction of a "normal" rat microbial flora. Rat colonic mucin. J Exp Anim Sci. 1992;35:110-9. PMID: 1295576

51. Sharma R, Schumacher U. Morphometric analysis of intestinal mucins under different dietary conditions and gut flora in rats. Dig Dis Sci. 1995;40:2532-9 PMID: 8536508

52. Meslin JC, Fontaine N, Andrieux C. Variation of mucin distribution in the rat intestine, caecum and colon: effect of the bacterial flora. Comp Biochem Physiol A. 1999;123:235-9. PMID: 10501018

53. Forstner JF, Oliver MG, Sylvester FA. Production, structure and biologicrelevance of gastrointestinal mucins. In: Blaser MJ, Smith PD, Ravdin JI,Greenberg HB, Guerrant $\mathrm{RL}$ (editors). Infections of the gastrointestinal tract. NewYork: Raven Press; 1995. p.71-88.

54. Kim YS, Ho SB. Intestinal goblet cells and mucins in health and disease:recent insights and progress. Curr Gastroenterol Rep. 2010;12:319-30. doi: 10.1007/ s11894-010-0131-2

55. Pelaseyed T, Bergström JH, Gustafsson JK, Ermund A, Birchenough GM, Schütte $A$, van der Post $S$, Svensson $F$, Rodríguez-Piñeiro AM, Nyström EE, Wising $C$, Johansson $\mathrm{ME}$, Hansson GC. The mucus and mucins of the goblet cells and enterocytes provide the first defense line of the gastrointestinal tract and interact with the immune system. Immunol Rev. 2014;260(1):8-20. doi: 10.1111/imr.12182

56. Lavie CJ, De Schutter A, Parto P, Jahangir E, Kokkinos $P$, Ortega FB, Arena R, Milani RV I. Obesity and prevalence of cardiovascular diseases and prognosis: the obesity paradox updated. Prog Cardiovasc Dis. 2016;58:537-47. PMID: 26826295

57. Lavie CJ, Arena R, Alpert MA, Milani RV, Ventura HO. Management of cardiovascular diseases in patients with obesity. Nat Rev Cardiol. 2018;15:45-56. PMID: 28748957

58. Lavie CJ, Laddu D, Arena R, Ortega FB, Alpert MA, Kushner RF. Healthy weight and obesity prevention: JACC Health Promotion Series. J Am Coll Cardiol. 2018;72(13):150631. doi: 10.1016/j.jacc.2018.08.1037

59. UNICEF/WHO/World Bank. Joint Child Malnutrition Estimates. 2018. 


\section{Correspondence:}

Dra. Flávia Emi Akamatsu

Rua Alexandre Dumas, 1410/154

04717-003 São Paulo - SP Brasil

Tel.: (55 11)3061-8277 / 97151-5516

flaea@usp.br

Received: Feb 21, 2019

Reviewed: Apr 19, 2019

Accepted: May 23, 2019
Conflict of interest: none

Financial source: none

${ }^{1}$ Research performed at the Laboratory of Descriptive and Topographic Anatomy Division (LIM 02), Laboratory of Surgical Physiopathology (LIM 62), and Center for Study and Research in Surgery (CEPEC), Department of Surgery, Faculty of Medicine, Universidade de São Paulo (FMUSP), Brazil.

This is an Open Access article distributed under the terms of the Creative Commons Attribution License, which permits unrestricted use, distribution,

and reproduction in any medium, provided the original work is properly cited. 